\title{
sciendo
}

Transport and Telecommunication, 2021, volume 22, no. 2, 217-229

Transport and Telecommunication Institute, Lomonosova 1, Riga, LV-1019, Latvia

DOI 10.2478/ttj-2021-0017

\section{A RELIABILITY-EXPLOITATION ANALYSIS OF A STATIC CONVERTER TAKING INTO ACCOUNT ELECTROMAGNETIC INTERFERENCE}

\author{
Jacek Paś ${ }^{1}$, Adam Rosiński', Kamil Białek ${ }^{3}$ \\ ${ }^{I}$ Military University of Technology, Faculty of Electronic, Institute of Electronic Systems \\ gen. Sylwestra Kaliskiego 2, 00-908 Warsaw, Poland \\ jacek.pas@wat.edu.pl \\ ${ }^{2}$ Warsaw University of Technology, Faculty of Transport, \\ Department of Telecommunications in Transport \\ Koszykowa 75, 00-662 Warsaw, Poland \\ adro@wt.pw.edu.pl \\ ${ }^{3}$ Railway Institute, Laboratory of Automation and Telecommunications \\ Chtopickiego 50, 04-275 Warsaw, Poland \\ kbialek@ikolej.pl
}

\begin{abstract}
The paper presents issues associated with the impact of electromagnetic interference on static converters, which exploitation in a railway transport environment. The measurements of an electromagnetic field emitted by a static converter were shown. Designs of this kind are exploitation in railway facilities, therefore, they should not disturb the functioning of other equipment, the rail traffic control systems, in particular. As a result of the EMC tests, it was concluded that the permissible values of conducted interference emissions were exceeded. An analysis of the obtained results enabled developing a research model, and a further reliability and exploitation analysis, taking into account electromagnetic interference. This, in turn, enabled determining a relationship allowing to determine the probability of a static converter staying in a state of full ability. The presented discussions regarding a static converter, taking into account electromagnetic interference, allow for the numerical assessment of different types of solutions (technical and organizational), which can be implemented in order to mitigate the impact of electromagnetic interference on a system's functioning.
\end{abstract}

Keywords: exploitation, reliability, electromagnetic interference, modelling, static converter

\section{Introduction}

Static converters exploitation in railway transport (especially in moving objects), most often function in diverse exploitation conditions. The observations of their exploitation process in a railway environment (Siergiejczyk et al., 2016; Sunitha and Thomas, 2018) confirm the dependency of their correct exploitation on the reliability of their components, and an efficient exploitation management process (Chrzan, 2018; Dyduch et al., 2011; Paś, 2015; Urbaniak et al., 2019). Therefore, a thorough analysis of static converters should take into account not only their reliability but also the efficiency of exploitation management (Siergiejczyk et al., 2015a). For this purpose, the authors imitated the phenomena undergoing in reality (taking into account electromagnetic interference) in a research model of a static converter.

Static converters are currently very often used in transport systems. Their task (in a railway vehicle) is to convert the constant traction voltage of $3000 \mathrm{~V}$ DC to low three-phase voltage $400 \mathrm{~V}$ AC and constant $24 \mathrm{~V}$ DC. The $400 \mathrm{~V}$ AC voltage is used to supply, i.a., auxiliary devices with high power demand (e.g. compressor drive motor). The $24 \mathrm{~V} \mathrm{DC}$ voltage is used to supply, i.a., lighting system, signalling system, as well as onboard computers and control systems. The correct exploitation of a converter has a significant impact on the safety and efficiency of a transportation process. The state of unreliability of safety of these devices may lead to safety hazards. The theory of reliability deals with, among others, the analysis of damage impact on specified reliability indicators (Billinton and Allan, 1996; Girón et al., 2018; Piegdoń et al., 2018). The area of interest of the theory of safety includes the results of damages, which may lead to safety hazards (especially important from the point of view of a passenger and good transport process). Therefore, the issue of correctly defining, which state can be deemed permissible or unacceptable from the point of view of safety (the impendency over safety states) is very important.

Increasing the safety level of transport systems can be achieved by, among others, improving their reliability parameters. The reliability of a converter is impacted by both the reliability of its components, as well as the use of redundant structures. The first solution is aimed at preventing damage. In the second 
case, the use of redundancy, although leading to an expansion of the converter, enables tolerating the occurring damage (through the introduction of the impendency over safety states) (Caban and Walkowiak 2019). The quality of information (Siergiejczyk et al., 2017; Stawowy and Kasprzyk, 2015; Stawowy and Siergiejczyk, 2017; Stawowy et al., 2017) obtained by systems from the sensors (Dabrowski et al., 2012; Kaniewski et al., 2017; Łabowski and Kaniewski, 2015; Reddig et al., 2018; Bednarek et al., 2019) is also important during a reliability-exploitation analysis. Certain scientific papers propose that scientific discussions apply the principles of artificial neural networks (Duer, 2012; Krzykowska and Krzykowski, 2019) or fuzzy logic (Losurdo et al., 2017). Functioning of static converters is also significantly impacted by the vibrations generated as a result of vehicle movement (Burdzik et al., 2013; Kostrzewski, 2018; Kukulski et al., 2019) but they are not taken into account in this article.

The impact of electromagnetic interference on the exploitation of various electrical and electronic devices used in transport has been attempted by scientists and engineers for a long time (Melit et al., 2014, Niknejad, 2007, Piersanti et al., 2018, Matyszkiel et al., 2019). The analyses concern not only mobile means of transport but also stationary facilities (Kolarovszki et al., 2013). However, there are still no detailed elaborations containing both the deliberations in the field of electromagnetic compatibility measurements, as well as the reliability-exploitation analysis of static converters.

Among others, the evaluation of electromagnetic compatibility taking into account the impact of atmospheric discharges on the exploitation of electronic devices has been, so far, discussed in regard to railway transport. The electronic devices used in transport are, i.a., rail traffic control systems, systems installed at level crossings, GSM-R (Global System for Mobile Communications - Railway), visual monitoring systems, etc. The analyses in that field were presented in the paper (Vašata and Doleček, 2016). The authors described various implemented methods of protection against adverse phenomena of this type. They also suggested solutions increasing the efficiency of the protection against discharges (i.a., through arrangement of electronic devices adequate to the environmental conditions already at the engineering stage of protection systems and elements).

The paper (Lheurette, 2013) should be cited among the most interesting scientific positions in the field of ensuring electromagnetic compatibility of electrical systems and devices. The elaboration describes issues associated with using various materials for the construction of mobile means of transport and their impact (including screening) on satisfying the requirements of electromagnetic compatibility.

A separate group of papers include the deliberations in the field of electromagnetic interference and electromagnetic compatibility of static converters. The authors of these positions present a generic approach towards this issue, not always taking into account the specific nature of rail transport and the requirements therein.

The paper (Nicolae et al., 2010) presents issues regarding electromagnetic interference generated by static converters. It was shown that the permissible values of electromagnetic interference were exceeded, which is why the use of a filter was suggested. Repeated measurements confirmed the lack of exceeding limit values, hence, the validity of the adopted concept.

The issue of studying static converters in terms of electromagnetic interference was described in (Gharbi and Hasnaoui, 2014). In order to meet the EMI requirements, the authors suggested the use of passive filters. They conducted computer simulations with the use of a SPICE computer environment, confirming that the guidelines in standards 55016-2-1, EN 50121-3-2 were met. Next, they conducted experimental tests, which confirmed the validity of the conducted computer simulations.

The previous considerations (presented above) in the field of electromagnetic compatibility of static converters, taking into account electromagnetic interference, and the suggestions of solutions decreasing the level of electromagnetic interference, do not take reliability-exploitation modelling into account. This is why, the authors of this article decided to adopt such an approach, while bearing in mind the specificity of rail transport and the applicable normative requirements (RajaPriyanka et al., 2017; White et al., 2006; Wróbel, 2018).

The paper presents the measurements of an electromagnetic field emitted by a static converter. Solutions of this kind are installed in mobile railway objects, therefore, they should not disturb the functioning of other equipment, the rail traffic control systems, in particular. An analysis of the obtained results enabled developing a research model, and a further reliability-exploitation analysis, taking into account electromagnetic interference.

\section{Reliability-Exploitation Analysis of a Static Converter Taking into Account the Electromagnetic Interference}

The electromagnetic compatibility studies of a static converter were conducted with the use of a test bench (Figure 1). An EMI receiver of the ESCI3 type and a TK $9420 \mathrm{HV}$ measuring probe were used. The used measuring equipment satisfied the requirements of the standard (PN-EN 55016-4-2:2011 + A1:2014). 
The measurements were conducted as per the methodology presented in the standard (PN-EN 55016-21:2014). Electromagnetic radiation limit values were adopted as per the guidelines included in the standard for railway object (PN-EN 50121-3-2:2017).

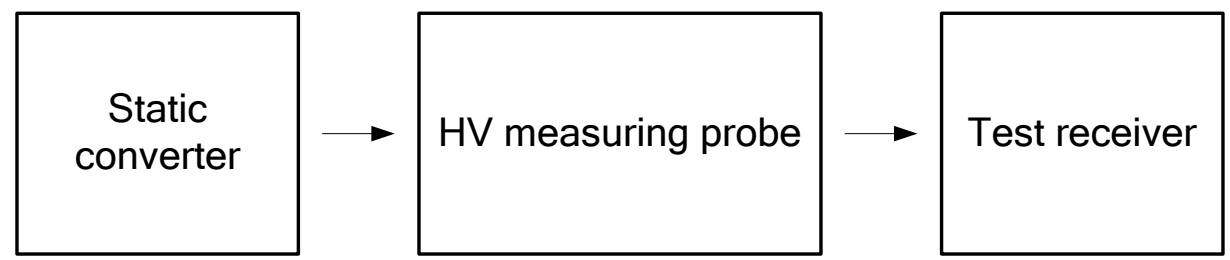

Figure 1. Measuring system block diagram

A static converter with the following technical parameters was tested:

- supply voltage $3 \mathrm{kV}$ DC,

- power $120 \mathrm{kVA}$,

- output AC voltage: 3x $400 \mathrm{~V}$,

- output DC voltage: $24 \mathrm{~V}$,

- overall efficiency: $>90 \%$,

- exploitation temperature: $-40^{\circ} \mathrm{C} \div+50^{\circ} \mathrm{C}$.

The conducted interference emission measurement was conducted on a $3 \mathrm{kV} \mathrm{DC}$ input port.

The tests started with measurements of the static converter, with reported incorrectly selected input filter parameters (i.e. frequency band and rejection value for unwanted out-of-band signals)

Measurement of an asymmetric component between the $+3 \mathrm{kV}$ cable and the static converter casing is shown in Figure 2. Measurement of an asymmetric component between the $+3 \mathrm{kV}$ cable and the static converter casing is shown in Figure 3. The limit values specified in relevant standards are exceeded in both cases.

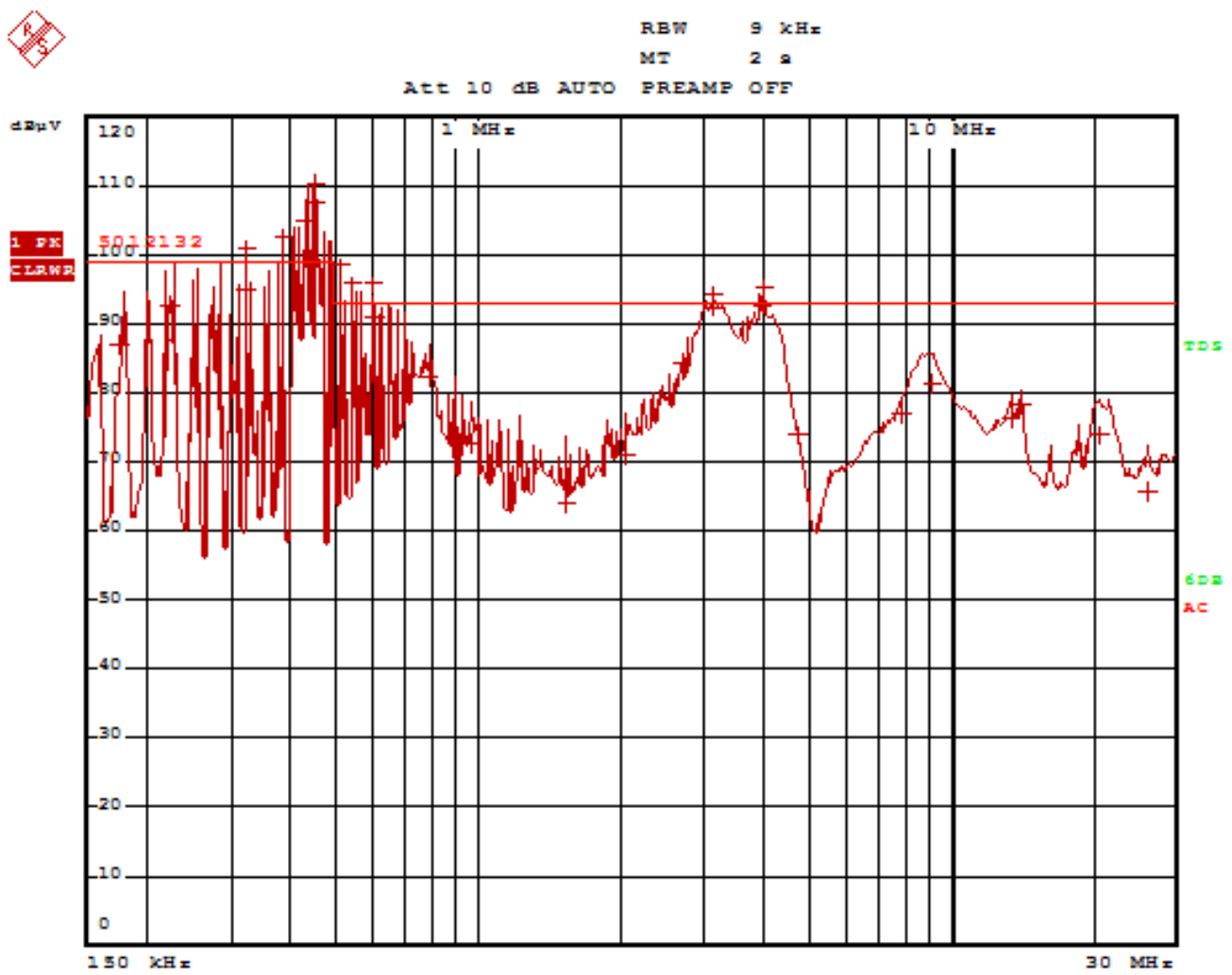

Figure 2. Measurement of an asymmetric component between the $+3 \mathrm{kV}$ cable and the static converter casing

Table 1 shows the values of frequencies where the limit levels of conducted interference emissions were exceeded. 
Table 1. The values of frequencies with reported exceeded limit levels of conducted interference emissions between a $+3 \mathrm{kV}$ cable and a converter casing, and a $-3 \mathrm{kV}$ cable and a converter casing

\begin{tabular}{|l|l|l|l|}
\hline $\begin{array}{l}\text { Frequency value } \\
{[\mathbf{k H z}]}\end{array}$ & $\begin{array}{l}\text { Interference signal amplitude value } \\
\mathbf{U}[\mathbf{d B} \boldsymbol{\mu} \mathbf{V}] \mathbf{f o r}:+\mathbf{3} \mathbf{k V} \text { cable and converter } \\
\text { casing }\end{array}$ & $\begin{array}{l}\text { Frequency } \\
\text { value } \\
\mathbf{k H z}]\end{array}$ & $\begin{array}{l}\text { Interference signal amplitude value } \\
\mathbf{U}[\mathbf{d B} \boldsymbol{\mu V}] \mathbf{f o r}: \mathbf{- 3} \mathbf{k V} \text { cable and converter } \\
\text { casing }\end{array}$ \\
\hline 322 & 101 & 358 & 101 \\
\hline 390 & 103 & $\begin{array}{l}382 \\
\text { /entire band/ }\end{array}$ & max 110 \\
\hline $\begin{array}{l}400-500 \\
\text { /entire band/ }\end{array}$ & max 110 & $\begin{array}{l}500-600 \\
\text { /entire band/ }\end{array}$ & max 98 \\
\hline $\begin{array}{l}500-600 \\
\text { /entire band/ }\end{array}$ & max 98 & 3182 & 95 \\
\hline 3130 & 94 & 3978 & 96 \\
\hline 4014 & 95 & & \\
\hline
\end{tabular}

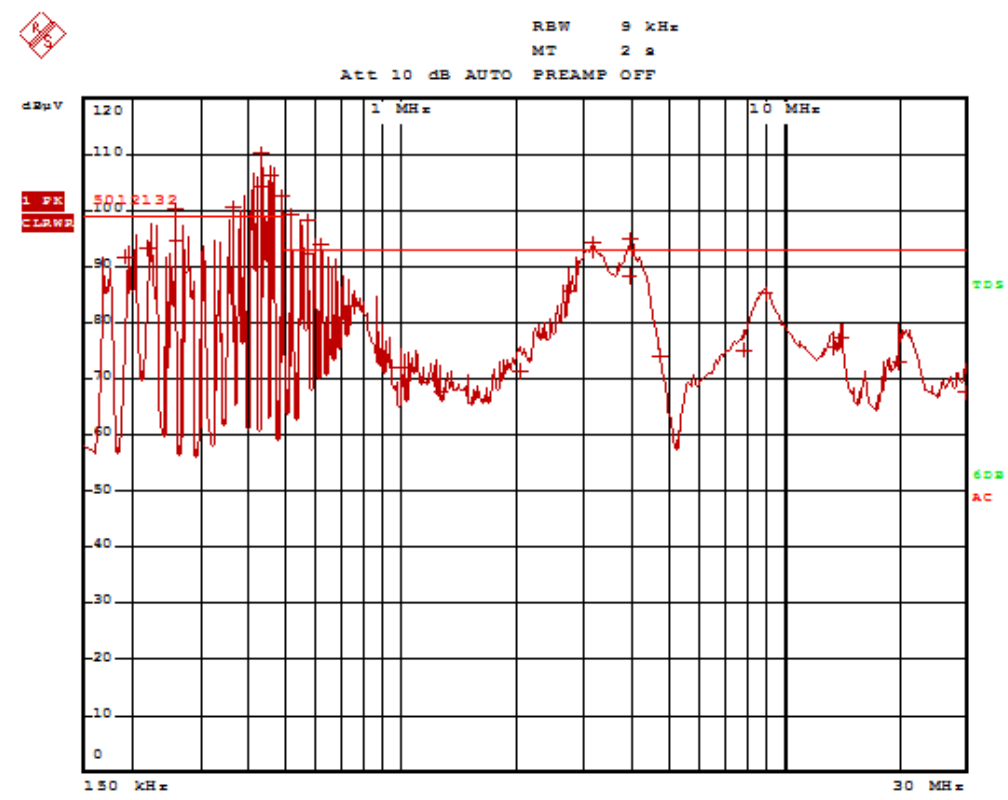

Figure 3. Measurement of an asymmetric component between the $-3 \mathrm{kV}$ cable and the static converter casing

The studies concerning the electromagnetic compatibility of conducted interference emissions of railway devices are in accordance with the methodology set out in the standard PN-EN 55016-2-1 for an asymmetric component of radioelectric disturbance voltage over a frequency range from $150 \mathrm{kHz}$ to 30 $\mathrm{MHz}$, divided into two frequency sub-ranges:

- $150 \mathrm{kHz} \div 500 \mathrm{kHz}$,

- $500 \mathrm{kHz} \div 30 \mathrm{MHz}$.

The limit levels of conducted interference emissions included in PN-EN 50121-3-2 are shown in Figure 4.

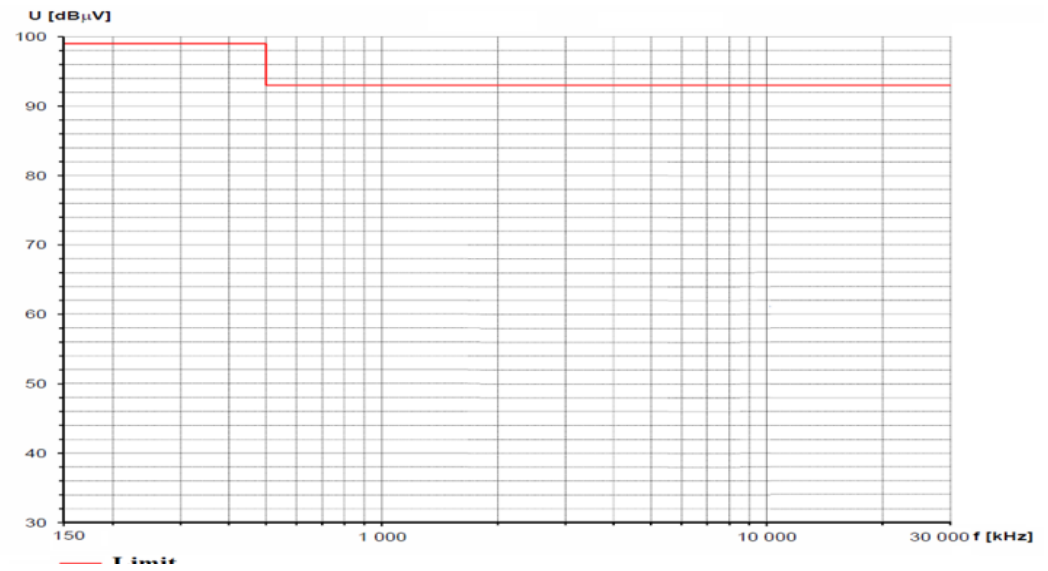

Figure 4. The permissible conducted interference emission values for a selected frequency band 
In order to decrease the electromagnetic interference and meeting the requirements set out in the standards for railway equipment, it was decided to correct the filter parameters through adding capacitance of a specific value. Measurement of an asymmetric component between the $+3 \mathrm{kV}$ cable and the static converter casing is shown in Figure 5. Measurement of an asymmetric component between the $+3 \mathrm{kV}$ cable and the static converter casing is shown in Figure 6 . The limit values are not exceeded in any of the two cases. Table 2 shows the values of interference signal amplitudes prior to and after using the filter with capacitance, and the differences resulting from attenuation introduced by the electronic system.

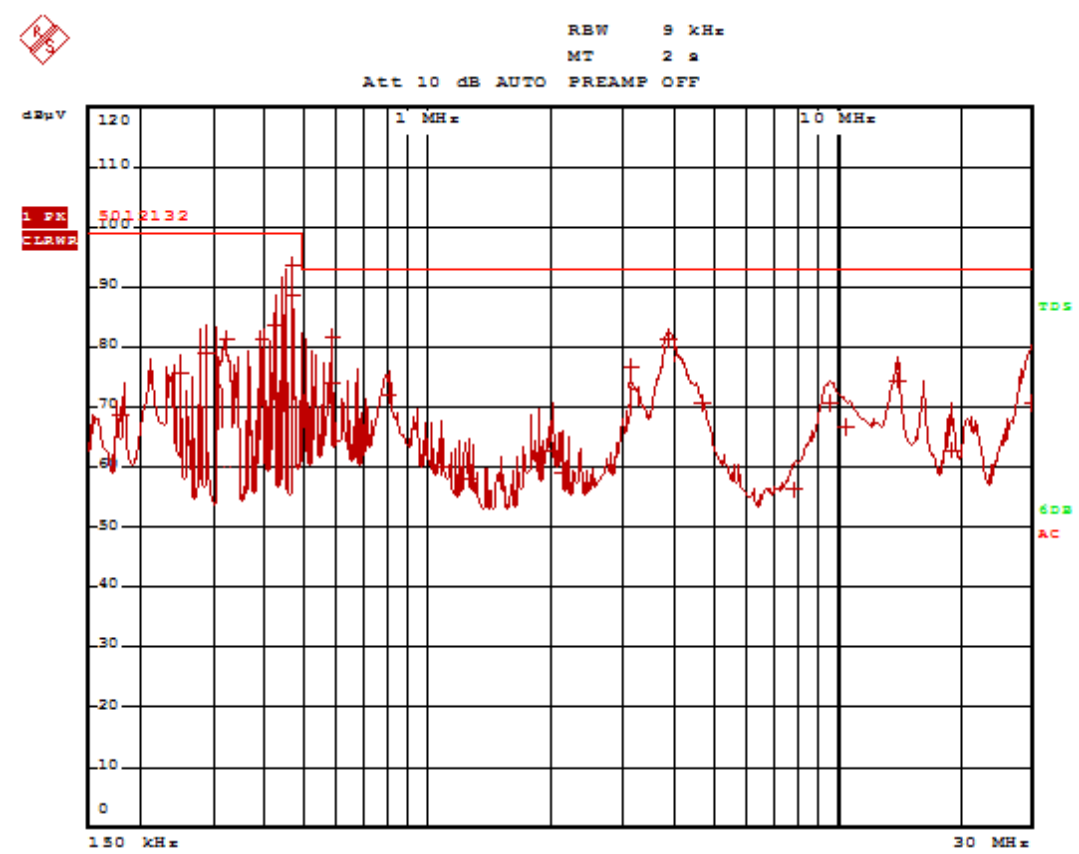

Figure 5. Measurement of an asymmetric component between the $+3 \mathrm{kV}$ cable and the static converter casing (after correcting filter parameters)

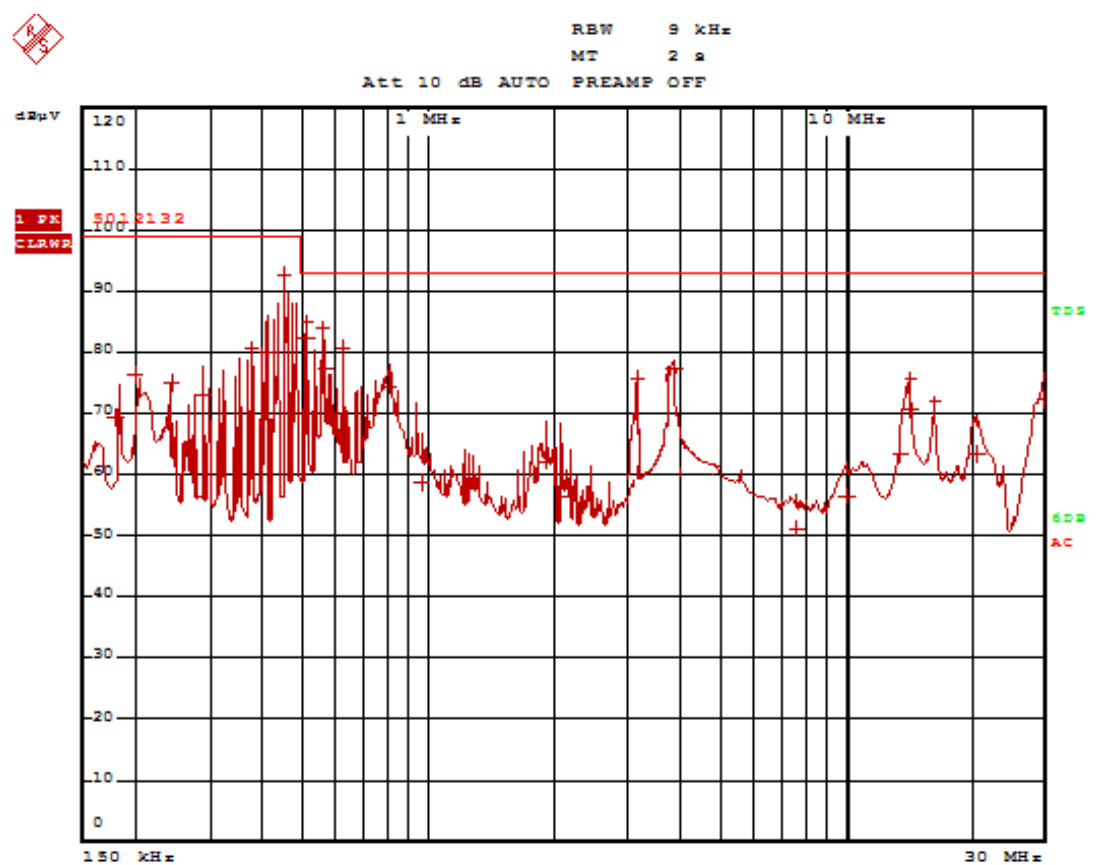

Figure 6. Measurement of an asymmetric component between the $-3 \mathrm{kV}$ cable and the static converter casing (after correcting filter parameters) 
Table 2. Values of interference signal amplitudes prior to and after using the filter with capacitance, and the differences resulting from attenuation introduced by the electronic system

\begin{tabular}{|c|c|c|c|c|c|c|c|}
\hline \multirow[t]{2}{*}{$\begin{array}{l}\text { Frequency } \\
\text { value [kHz] }\end{array}$} & \multicolumn{3}{|c|}{$\begin{array}{l}\text { Interference signal amplitude value } \\
U[d B \mu V] \text { for: }+3 \mathrm{kV} \text { cable and converter } \\
\text { casing, rejection value } U[\mathrm{~dB} \mu \mathrm{V}]\end{array}$} & \multirow[t]{2}{*}{$\begin{array}{l}\text { Frequency } \\
\text { value } \\
{[\mathrm{kHz}]}\end{array}$} & \multicolumn{3}{|c|}{$\begin{array}{l}\text { Interference signal amplitude value } \\
\mathrm{U}[\mathrm{dB} \mu \mathrm{V}] \\
\text { for: }-3 \mathrm{kV} \text { cable and converter casing } \\
\text { rejection value } \mathrm{U}[\mathrm{dB} \mu \mathrm{V}]\end{array}$} \\
\hline & no filter & filter & rejection & & no filter & filter & rejection \\
\hline 322 & 101 & 81 & 20 & 258 & 101 & 75 & 26 \\
\hline 390 & 103 & 81 & 22 & 382 & 102 & 81 & 21 \\
\hline $\begin{array}{l}400-500 \\
\text { /entire band/ }\end{array}$ & $\max 110$ & $\max 94$ & 16 & $\begin{array}{l}400-500 \\
\text { /entire band/ }\end{array}$ & $\max 110$ & 93 & 17 \\
\hline $\begin{array}{l}500-600 \\
\text { /entire band/ }\end{array}$ & $\max 98$ & $\max 82$ & 16 & $\begin{array}{l}500-600 \\
\text { /entire band/ }\end{array}$ & $\max 98$ & 84 & 14 \\
\hline 3130 & 94 & 77 & 17 & 3182 & 95 & 76 & 19 \\
\hline 4014 & 95 & 82 & 13 & 3978 & 96 & 77 & 19 \\
\hline
\end{tabular}

In the course of analysing the measurement results, it can be concluded that a static converted exploitation in a transport environment (with electromagnetic interference) can stay in defined states (Siergiejczyk et al., 2015). Therefore, it was decided to conduct a reliability-exploitation analysis (Siergiejczyk et al., 2017; Wasiak et al., 2019; Klimczak and Paś, 2019). Conducting the analysis will provide relationships, which allow the determination of the probability values of the system being in the distinguished exploitation states.

The external electromagnetic field penetrates into the circuits of the static converter through the coupling mechanism producing interference. The electronic components of the static converter (Figure 7) are exposed to an external, unintentional electromagnetic field (PEM) from a specific frequency band. In this case, the transmission bus connecting the devices with the static converter is an unintentional receiving antenna that picks up the interference generated by the interference current. This coupling arises as a result of the PEM effect on the cable that transmits useful signals. The interference signal induced in the bus is suppressed by the shield of the transmission bus cable. The attenuation of the cable does not reach a large value, so part of the interference signal gets along with the useful signal to the static converter. It causes the changes of the reference potential (ground) of the static converter as a result of coupling through common impedance $Z$ and ground loop. In a static converter (as a railway device) two types of coupling can be distinguished, series coupling (PEM) and parallel (through elements Z, C at the output operational amplifier $\mathrm{OA}$ ). The following elements implement the coupling with PEM: it is the reference impedance $\mathrm{Z}$, capacity $\mathrm{C}$ in relation to the metal cover of the entire railway device. These couplings can be minimized by reducing the parasitic capacity, or by reducing the rapid voltage changes occurring at $\mathrm{C}$. Additional interference voltage also occurs in the ground loop for the entire device. This can also cause feedback through so-called crosstalk (inductive or capacitive). Especially in electrical wires that are near interference sources, i.e. $U_{\text {zak }}$ voltage, the occurrence of a static voltage drop in the static converter may generate an alternating electric and magnetic field around this conductor. The alternating electric and magnetic field generates current and voltage, causing interference in cables near the transmission bus through capacitive crosstalk interference that affects other devices. Interference values are proportional to the rate of change of voltage (effect through capacitance - C) or current (effect through inductance - ground loop) over time.

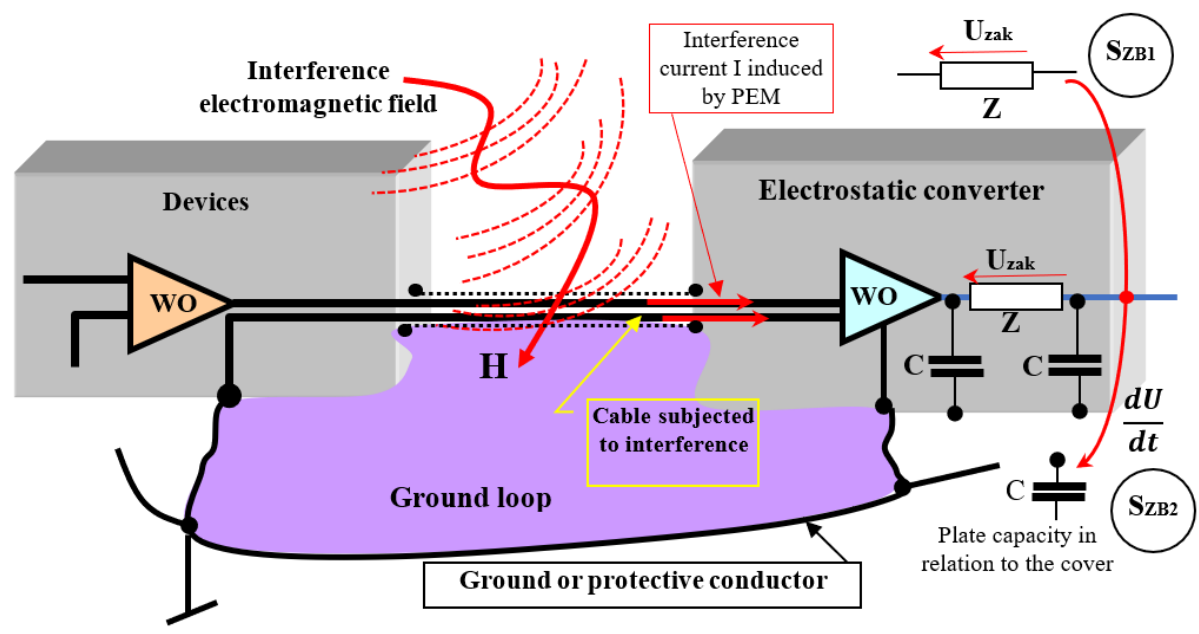

Figure 7. Input circuits of the electrostatic converter subject to unintended electromagnetic interference 
By conducting an exploitation analysis regarding a static converter, it is possible to illustrate the relationships occurring in such a structure, in terms of reliability and exploitation, as presented in Figure 8.

When determining the intensity of transitions between the distinguished states, the factor of electromagnetic interference $\Gamma$ on the analyzed static converter was taken into account. Its value is in the range:

$\Gamma \in\langle 0,1\rangle$.

We assume that:

- $\Gamma=0$ in the absence of electromagnetic interference (the protection measures used completely eliminate the influence of electromagnetic interference on the static converter),

- $\Gamma=1$ for the impact of electromagnetic interference (no protective measures are in place to reduce the effects of electromagnetic interference on a static converter).

The electromagnetic interference factor $\Gamma$ on the analyzed static converter can be used to select rational solutions that reduce the impact of electromagnetic interference (Paś et al., 2020).

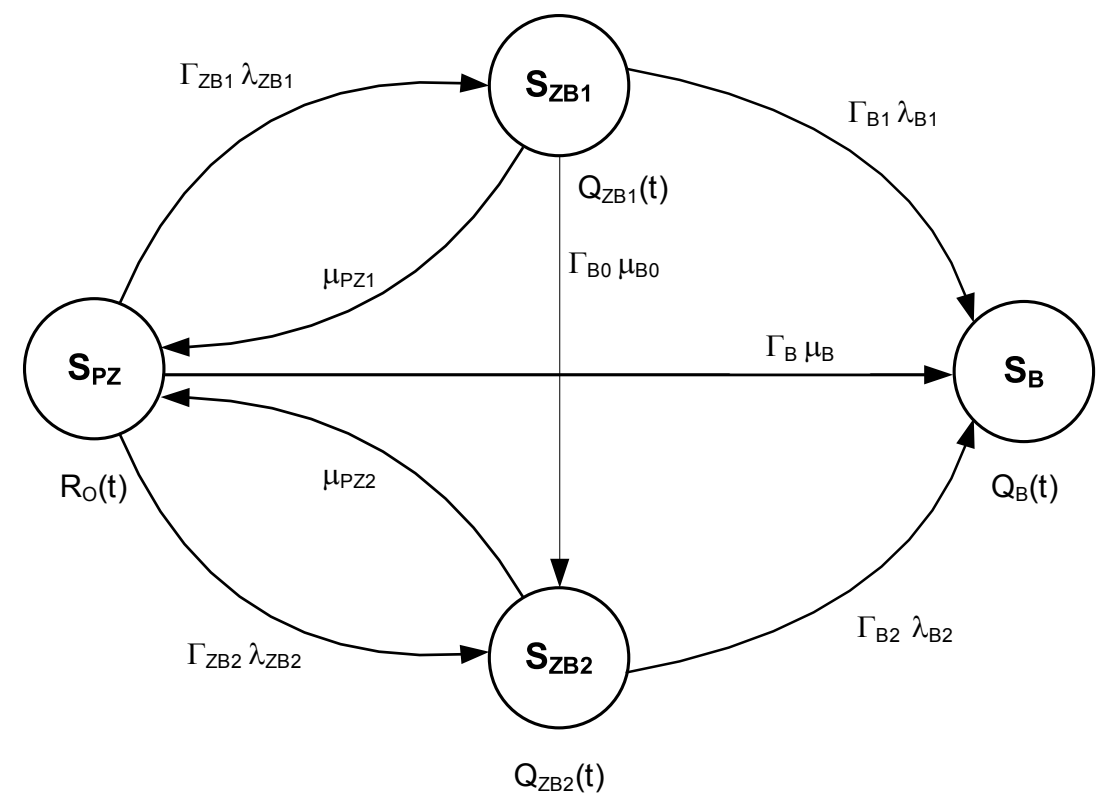

Figure 8. Relations in a static converter, taking into account electromagnetic interference Marking in the Figure 8:

$\mathrm{R}_{\mathrm{O}}(\mathrm{t})$ - the probability function of the system staying in the state of full ability $\mathrm{S}_{\mathrm{PZ}}$,

$\mathrm{Q}_{\mathrm{ZB} 1}$ - the probability function of a system staying in a state of the impendency over safety I $\mathrm{S}_{\mathrm{ZB} 1}$,

$\mathrm{Q}_{\mathrm{ZB} 2}$ - the probability function of a system staying in a state of the impendency over safety II $\mathrm{S}_{\mathrm{ZB} 2}$,

$\mathrm{Q}_{\mathrm{B}}(\mathrm{t})$ - the probability function of a system staying in a state of unreliability of safety $\mathrm{S}_{\mathrm{B}}$,

$\lambda_{\mathrm{ZB} 1}$ - intensities of transition from a state of full ability I $\mathrm{S}_{\mathrm{PZ}}$ to a state of the impendency over safety I S $\mathrm{S}_{\mathrm{ZB} 1}$,

$\Gamma_{\mathrm{ZB} 1}$ - the electromagnetic interference factor for the transition intensity $\lambda_{\mathrm{ZB} 1}$,

$\lambda_{\mathrm{ZB} 2}$ - intensities of transition from a state of full ability II $\mathrm{S}_{\mathrm{PZ}}$ to a state of the impendency over safety II $\mathrm{S}_{\mathrm{ZB} 2}$,

$\Gamma_{\mathrm{ZB} 2}-$ the electromagnetic interference factor for the transition intensity $\lambda_{\mathrm{ZB} 2}$,

$\mu_{\mathrm{PZ} 1}$ - intensities of transition from a state of the impendency over safety I $\mathrm{S}_{\mathrm{ZB} 1}$ to a state of full ability $\mathrm{S}_{\mathrm{PZ}}$, $\mu_{\mathrm{PZ} 2}-$ intensities of transition from a state of the impendency over safety II $\mathrm{S}_{\mathrm{ZB} 2}$ to a state of full ability $\mathrm{S}_{\mathrm{PZ}}$, $\mu_{\mathrm{B} 0}$ - intensities of transition from a state of the impendency over safety I $\mathrm{S}_{\mathrm{ZB} 1}$ to a state of full ability II $\mathrm{S}_{\mathrm{PZ}}$,

$\Gamma_{\mathrm{B} 0}$ - the electromagnetic interference factor for the transition intensity $\mu_{\mathrm{B} 0}$,

$\mu_{\mathrm{B} 1}$ - intensities of transition from a state of full ability $\mathrm{S}_{\mathrm{PZ}}$ to a state of unreliability of safety $\mathrm{S}_{\mathrm{B}}$,

$\lambda_{\mathrm{B} 1}$ - intensities of transition from a state of the impendency over safety $\mathrm{I}_{\mathrm{ZB} 1}$ to a state of unreliability of safety $\mathrm{S}_{\mathrm{B}}$,

$\Gamma_{\mathrm{B} 1}$ - the electromagnetic interference factor for the transition intensity $\lambda_{\mathrm{B} 1}$,

$\lambda_{\mathrm{B} 2}$ - intensities of transition from a state of the impendency over safety II $\mathrm{S}_{\mathrm{ZB} 2}$ to a state of unreliability of safety $\mathrm{S}_{\mathrm{B}}$

$\Gamma_{\mathrm{B} 2}-$ the electromagnetic interference factor for the transition intensity $\lambda_{\mathrm{B} 2}$,

$\lambda_{\mathrm{B}}-$ intensities of transition from a state of full ability I $\mathrm{S}_{\mathrm{PZ}}$ to a state of unreliability of safety $\mathrm{S}_{\mathrm{B}}$,

$\Gamma_{B}-$ the electromagnetic interference factor for the transition intensity $\lambda_{B}$.

The state of full ability $\mathrm{S}_{\mathrm{PZ}}$ is a state, in which a static converter functions correctly. The impendency over safety $\mathrm{I}_{\mathrm{ZB} 1}$ is a state in which a static converter is partially fit (parallel coupling through mutual impedance). The impendency over safety II $\mathrm{S}_{\mathrm{ZB} 2}$ is a state in which a static converter is 
partially fit (parallel coupling through board capacity relative to the casing). Unreliability of safety $\mathrm{S}_{\mathrm{B}}$ is a state in which a static converter is unfit (electromagnetic interference exceed limit values).

If a static converter is in a state of full ability $\mathrm{S}_{\mathrm{PZ}}$ and the interference appears in the form of parallel coupling through common impedance, then the system switches to a state of the impendency over safety I $S_{Z B 1}$ with the intensity of $\lambda_{Z B 1}$. If a static converter is in the state of the impendency over safety I $\mathrm{S}_{\mathrm{ZB} 1}$, then it is possible to switch to the state of full ability $\mathrm{S}_{\mathrm{PZ}}$, provided that actions are taken aimed at restoring the fitness state.

In the event of a state of the impendency over safety $\mathrm{I}_{\mathrm{ZB} 1}$ and the interference exceeding permissible values, the a static converter moves to a state of unreliability of safety $\mathrm{S}_{\mathrm{B}}$ with an intensity of $\lambda_{\mathrm{B} 1}$.

If a static converter is in a state of full ability $\mathrm{S}_{\mathrm{PZ}}$ and the interference appears in the form of parallel coupling through board capacitance relative to the casing, then the system switches to a state of the impendency over safety II $S_{\mathrm{ZB} 2}$ with the intensity of $\lambda_{\mathrm{ZB} 2}$. If a static converter is in the state of the impendency over safety II $\mathrm{S}_{\mathrm{ZB} 2}$, then it is possible to switch to the state of full ability $\mathrm{S}_{\mathrm{PZ}}$, provided that actions are taken aimed at restoring the fitness state.

In the event of a state of the impendency over safety II $\mathrm{S}_{\mathrm{ZB} 2}$ and the interference exceeding permissible values, a static converter moves to a state of unreliability of safety $S_{B}$ with an intensity of $\lambda_{B 2}$.

If a static converter is in a state of the impendency over safety I $S_{\mathrm{ZB} 1}$ and the interference changes from parallel coupling through common impedance to interference in the form of parallel coupling through board capacitance relative to the casing, a static converter switches to a state of the impendency over safety II $\mathrm{S}_{\mathrm{ZB} 2}$ with the intensity of $\mu_{\mathrm{B} 0}$.

If a static converter is in a state of full ability $\mathrm{S}_{\mathrm{PZ}}$ and the arising electromagnetic interference exceed the limit values, it moves to a state of unreliability of safety $S_{B}$ with the intensity of $\mu_{\mathrm{B} 1}$. equations:

A static converter illustrated in Figure 8 can be described by the following Chapman-Kolmogorov

$$
\begin{aligned}
& R_{0}^{\prime}(t)=-\Gamma_{Z B 1} \cdot \lambda_{Z B 1} \cdot R_{0}(t)+\mu_{P Z 1} \cdot Q_{Z B 1}(t)-\Gamma_{Z B 2} \cdot \lambda_{Z B 2} \cdot R_{0}(t)+\mu_{P Z 2} \cdot Q_{Z B 2}(t)-\Gamma_{B} \cdot \mu_{B} \cdot R_{0}(t) . \\
& Q_{Z B 1}^{\prime}(t)=\Gamma_{Z B 1} \cdot \lambda_{Z B 1} \cdot R_{0}(t)-\mu_{P Z 1} \cdot Q_{Z B 1}(t)-\Gamma_{B 1} \cdot \lambda_{B 1} \cdot Q_{Z B 1}(t)-\Gamma_{B 0} \cdot \mu_{B 0} \cdot Q_{Z B 1}(t) . \\
& Q_{Z B 2}^{\prime}(t)=\Gamma_{Z B 2} \cdot \lambda_{Z B 2} \cdot R_{0}(t)-\mu_{P Z 2} \cdot Q_{Z B 2}(t)-\Gamma_{B 2} \cdot \lambda_{B 2} \cdot Q_{Z B 2}(t)+\Gamma_{B 0} \cdot \mu_{B 0} \cdot Q_{Z B 1}(t) . \\
& Q_{B}^{\prime}(t)=\Gamma_{B 1} \cdot \lambda_{B 1} \cdot Q_{Z B 1}(t)+\Gamma_{B 2} \cdot \lambda_{B 2} \cdot Q_{Z B 2}(t)+\Gamma_{B} \cdot \mu_{B} \cdot R_{0}(t) .
\end{aligned}
$$

Given the initial conditions:

$R_{0}(0)=1$,

$Q_{Z B 1}(0)=Q_{Z B 2}(0)=Q_{B}(0)=0$

and Laplace transform yields the following system of linear equations:

$$
\begin{aligned}
& s \cdot R_{0}^{*}(s)-1=-\Gamma_{Z B 1} \cdot \lambda_{Z B 1} \cdot R_{0}^{*}(s)+\mu_{P Z 1} \cdot Q_{Z B 1}^{*}(s)-\Gamma_{Z B 2} \cdot \lambda_{Z B 2} \cdot R_{0}^{*}(s)+ \\
& +\mu_{P Z 2} \cdot Q_{Z B 2}^{*}(s)-\Gamma_{B} \cdot \mu_{B} \cdot R_{0}^{*}(s) . \\
& s \cdot Q_{Z B 1}^{*}(s)=\Gamma_{Z B 1} \cdot \lambda_{Z B 1} \cdot R_{0}^{*}(s)-\mu_{P Z 1} \cdot Q_{Z B 1}^{*}(s)-\Gamma_{B 1} \cdot \lambda_{B 1} \cdot Q_{Z B 1}^{*}(s)-\Gamma_{B 0} \cdot \mu_{B 0} \cdot Q_{Z B 1}^{*}(s) . \\
& s \cdot Q_{Z B 2}^{*}(s)=\Gamma_{Z B 2} \cdot \lambda_{Z B 2} \cdot R_{0}^{*}(s)-\mu_{P Z 2} \cdot Q_{Z B 2}^{*}(s)-\Gamma_{B 2} \cdot \lambda_{B 2} \cdot Q_{Z B 2}^{*}(s)+\Gamma_{B 0} \cdot \mu_{B 0} \cdot Q_{Z B 1}^{*}(s) . \\
& s \cdot Q_{B}^{*}(s)=\Gamma_{B 1} \cdot \lambda_{B 1} \cdot Q_{Z B 1}^{*}(s)+\Gamma_{B 2} \cdot \lambda_{B 2} \cdot Q_{Z B 2}^{*}(s)+\Gamma_{B} \cdot \mu_{B} \cdot R_{0}^{*}(s) .
\end{aligned}
$$

Transforming it, a record in the schematic (Laplace) view is obtained:

$$
\begin{aligned}
R_{0}^{*}(s)=- & \frac{b_{1} \cdot b_{2}}{b_{2} \cdot \Gamma_{Z B 1} \cdot \lambda_{Z B 1} \cdot \mu_{P Z 1}-a \cdot b_{1} \cdot b_{2}+b_{1} \cdot \Gamma_{Z B 2} \cdot \lambda_{Z B 2} \cdot \mu_{P Z 2}+} . \\
+ & \Gamma_{B 0} \cdot \mu_{B 0} \cdot \Gamma_{Z B 1} \cdot \lambda_{Z B 1} \cdot \mu_{P Z 2} \\
Q_{Z B 1}^{*}(s)=- & \frac{b_{2} \cdot \Gamma_{Z B 1} \cdot \lambda_{Z B 1}}{b_{2} \cdot \Gamma_{Z B 1} \cdot \lambda_{Z B 1} \cdot \mu_{P Z 1}-a \cdot b_{1} \cdot b_{2}+b_{1} \cdot \Gamma_{Z B 2} \cdot \lambda_{Z B 2} \cdot \mu_{P Z 2}+} . \\
& +\Gamma_{B 0} \cdot \mu_{B 0} \cdot \Gamma_{Z B 1} \cdot \lambda_{Z B 1} \cdot \mu_{P Z 2} \\
Q_{Z B 2}^{*}(s)=- & \frac{b_{1} \cdot \Gamma_{Z B 2} \cdot \lambda_{Z B 2}+\Gamma_{B 0} \cdot \mu_{B 0} \cdot \Gamma_{Z B 1} \cdot \lambda_{Z B 1}}{b_{2} \cdot \Gamma_{Z B 1} \cdot \lambda_{Z B 1} \cdot \mu_{P Z 1}-a \cdot b_{1} \cdot b_{2}+b_{1} \cdot \Gamma_{Z B 2} \cdot \lambda_{Z B 2} \cdot \mu_{P Z 2}+} . \\
& +\Gamma_{B 0} \cdot \mu_{B 0} \cdot \Gamma_{Z B 1} \cdot \lambda_{Z B 1} \cdot \mu_{P Z 2}
\end{aligned}
$$




$$
\begin{gathered}
b_{1} \cdot b_{2} \cdot \Gamma_{B} \cdot \mu_{B}+b_{2} \cdot \Gamma_{B 1} \cdot \lambda_{B 1} \cdot \Gamma_{Z B 1} \cdot \lambda_{Z B 1}+b_{1} \cdot \Gamma_{B 2} \cdot \lambda_{B 2} \cdot \Gamma_{Z B 2} \cdot \lambda_{Z B 2}+ \\
Q_{B}^{*}(s)=-\frac{+\Gamma_{B 0} \cdot \mu_{B 0} \cdot \Gamma_{B 2} \cdot \lambda_{B 2} \cdot \Gamma_{Z B 1} \cdot \lambda_{Z B 1}}{b_{2} \cdot \Gamma_{Z B 1} \cdot \lambda_{Z B 1} \cdot \mu_{P Z 1}-a \cdot b_{1} \cdot b_{2}+b_{1} \cdot \Gamma_{Z B 2} \cdot \lambda_{Z B 2} \cdot \mu_{P Z 2}+} \\
+\Gamma_{B 0} \cdot \mu_{B 0} \cdot \Gamma_{Z B 1} \cdot \lambda_{Z B 1} \cdot \mu_{P Z 2}
\end{gathered},
$$

where:

$a=s+\Gamma_{Z B 1} \cdot \lambda_{Z B 1}+\Gamma_{Z B 2} \cdot \lambda_{Z B 2}+\Gamma_{B} \cdot \mu_{B}$.

$b_{1}=s+\mu_{P Z 1}+\Gamma_{B 1} \cdot \lambda_{B 1}+\Gamma_{B 0} \cdot \mu_{B 0}$.

$b_{2}=s+\mu_{P Z 2}+\Gamma_{B 2} \cdot \lambda_{B 2}$.

$c=s$.

By conducting further mathematical analysis, we obtain relationships, which allow the determination of probabilities of a static converter staying in states of: full ability $\mathrm{S}_{\mathrm{PZ}}$, the impendency over safety $\mathrm{S}_{\mathrm{ZB} 1}$ and $\mathrm{S}_{\mathrm{ZB} 2}$, and unreliability of safety $\mathrm{S}_{\mathrm{B}}$.

\section{Modelling the Exploitation Process of a Static Converter, Taking into Account Electromagnetic Interference}

Simulation and computer methods and studies give an opportunity to determine influence of the reliability and maintenance parameters of particular elements on reliability of the entire system relatively fast.

Thanks to the computer assistance (mathematical program), it is possible to conduct the calculations enabling the determination of the probability $\mathrm{R}_{\mathrm{O}}$ of a static converter staying in a state of full ability $\mathrm{S}_{\mathrm{PZ}}$. Such a procedure is shown in the following example (it was assumed that no dedicated solutions were used to reduce the effects of electromagnetic interference on a static converter, and therefore $\Gamma=1$ ).

\section{Example}

Let us assume the following values describing the analysed a static converter:

- duration of research - 1 year (the value of this time is given in the units as hours $[h]$ ):

$t=8760[h]$

- intensity of transitions from a state of full ability to a state of the impendency over safety I $\lambda_{Z B 1}$ :

$\lambda_{Z B 1}=0.000001[1 / h]$;

- intensity of transitions from a state of full ability to a state of the impendency over safety II $\lambda_{Z B 2}$ :

$\lambda_{Z B 2}=0.0000001[1 / h]$;

- intensity of transitions from a state of the impendency over safety I to a state of unreliability of safety $\lambda_{B 1}$ :

$\lambda_{B 1}=0.0000001[1 / h]$

- intensity of transitions from a state of the impendency over safety II to a state of unreliability of safety $\lambda_{N 2}$ :

$\lambda_{B 2}=0.000001[1 / h]$

- intensity of transitions from a state of the impendency over safety I to a state of full ability $\mu_{B 0}$ :

$\mu_{B 0}=0.00000001[1 / h]$;

- intensity of transitions from a state of full ability to a state of unreliability of safety $\mu_{B 1}$ :

$\mu_{B}=0.00000001[1 / h]$;

- intensity of transitions from a state of the impendency over safety I to a state of full ability $\mu_{P Z 1}$ :

$\mu_{P Z 1}=0.1[1 / h] ;$

- intensity of transitions from a state of the impendency over safety II to a state of full ability $\mu_{P Z 2}$ :

$\mu_{P Z 2}=0.2[1 / h]$. 
The above values of damage intensity (marked with the symbol $\lambda$ ) were estimated on the basis of observation of the operation process of real systems (Chmielińska et al., 2016, Klimczak and Paś, 2019). Railway equipment is subject to a pre-aging process in production plants. Therefore, an exponential distribution model of airworthiness was used.

Knowing the value of the integrity $R_{\mathrm{ZB} 1}(t)$, there can be estimated the intensity of the transition from the state of full ability to the state of the impendency over safety I $\lambda_{Z B 1}$ :

$\lambda_{\mathrm{ZB} 1}=-\frac{\ln \mathrm{R}_{\mathrm{ZB} 1}(\mathrm{t})}{\mathrm{t}}$.

For $t=8760[h]$ and $R_{\mathrm{ZB} 1}(t)=0.991278$ we get:

$\lambda_{\mathrm{ZB} 1}=-\frac{\ln R_{\mathrm{ZB} 1}(t)}{t}=-\frac{\ln 0.991278}{8760}=0.000001\left[\frac{1}{h}\right]$.

Other damage intensities were calculated similarly.

The intensities of recovery of exploitation potential (marked with the symbol $\mu$ ) were also estimated on the basis of observation of the process of exploitation of real systems (Paś, 2015, Klimczak and Paś, 2019). In the case of exponential distribution, these are the inverse of time.

The following is obtained for the above input values, using the equation (5):

$$
\begin{aligned}
& 1.11 \cdot 10^{16} \cdot s+1 \cdot 10^{16} \cdot \mu_{P Z 1}+1.1 \cdot 10^{15} \cdot \mu_{P Z 2}+1.1 \cdot 10^{22} \cdot s^{2}+1 \cdot 10^{22} \cdot s \cdot \mu_{P Z 1}+ \\
R_{0}^{*}(s)= & +1 \cdot 10^{22} \cdot s \cdot \mu_{P Z 2}+1 \cdot 10^{22} \cdot \mu_{P Z 1} \cdot \mu_{P Z 2}+1.1 \cdot 10^{9} \\
& 1.3421 \cdot 10^{10} \cdot s+1.1 \cdot 10^{9} \cdot \mu_{P Z 1}+1.011 \cdot 10^{9} \cdot \mu_{P Z 2}+1 \cdot 10^{22} \cdot s^{2} \cdot \mu_{P Z 1}+ \\
& +1 \cdot 10^{22} \cdot s^{2} \cdot \mu_{P Z 2}+2.22 \cdot 10^{16} \cdot s^{2}+1 \cdot 10^{22} \cdot s^{3}+1.11 \cdot 10^{16} \cdot s \cdot \mu_{P Z 1}+ \\
& +1.12 \cdot 10^{16} \cdot s \cdot \mu_{P Z 2}+1 \cdot 10^{14} \cdot \mu_{P Z 1} \cdot \mu_{P Z 2}+1 \cdot 10^{22} \cdot s \cdot \mu_{P Z 1} \cdot \mu_{P Z 2}+1221
\end{aligned} .
$$

As a result of transformations, we obtain:

$$
R_{0}(t)=0.9999895 \cdot e^{-1.000139 \cdot 10^{-8} \cdot t}+5.00004299 \cdot 10^{-7} \cdot e^{-0.2000011 \cdot t}+0.0000099998 \cdot e^{-0.1000011 \cdot t} .
$$

As a final result, we obtain: $R_{O}=0.99990189$

If, for the data adopted in the above example, we assume the use of dedicated solutions reducing the effects of electromagnetic interference on the static converter, which result in a change in the value of all coefficients of the impact of electromagnetic interference on the value $\Gamma_{Z B 1}=\Gamma_{Z B 2}=\Gamma_{B 0}=\Gamma_{B 1}=$ $\Gamma_{B 2}=\Gamma_{B}=0.5$, then the calculations will result in:

$$
R_{0}(t)=0.9999947 \cdot e^{-1.000032 \cdot 10^{-8} \cdot t}+2.5000096 \cdot 10^{-7} \cdot e^{-0.2000005 \cdot t}+0.0000049999 \cdot e^{-0.10000055 \cdot t} .
$$

As a final result, we obtain: $R_{O}=0.99990715$

The presented reliability-exploitation analysis of a static converter, taking account of electromagnetic interference, enables numerical evaluation of different types of solutions (technical and organizational). This enables their implementation in order to mitigate the impact of internal and external electromagnetic interference (including the lack of a filter and the functioning of a filter matched to the extent of present interference) on the exploitation of a static converter.

It is also possible to use the developed model to determine the curves representing the dependencies of the probabilities of the static converter staying in the designated states as a function of the intensity of transitions between individual states. These issues will be explored by the authors in further research.

To sum up the considerations, it can be concluded that if the designers of static converters exploitation in rail transport are aware of the conditions of an electromagnetic environment (i.a., through measurements and reliability-exploitation analysis presented above) in which a system is to be probably functioning, then EMC requirements, which are usually known and can be taken into account at the device engineering stage, have to be met.

\section{Conclusions}

The current, very frequent use of static converters in numerous rail transport objects results in the necessity of their functioning in variable systems, located in close proximity. The effect of such technical and system solutions might be a case of increased level of electromagnetic interference, which impact the 
system. The lack of ensured external (interaction of, e.g., two devices) and internal (interference inside a given device) electromagnetic compatibility in a railway device means a possibility of exploitationally unacceptable transitions between specified states. This may cause incorrect functioning of a static converter, hence, it can stay in the states of the impendency over safety or unreliability of safety. This is why, designing static converters should include planning their functioning in actual conditions, that is, in an environment with other electronic and electric devices, which satisfy the requirements regarding the permissible emission levels for conducted and radiated electromagnetic interferences in defined conditions. The presented reliability-exploitation analysis of a static converter, taking into account electromagnetic interference, may become helpful in that matter. It enables to numerically determine the value of probabilities of a converter staying in distinguished states in the course of electromagnetic interference, within a selected frequency range.

In further research concerning this issue, the authors plan to further develop reliability-exploitation models, which will differentiate between the states of the impendency over safety. This will allow a more accurate mapping of static converter functioning in an electromagnetic railway environment.

\section{References}

1. Bednarek, M., Dąbrowski, T., Olchowik, W. (2019) Selected practical aspects of communication diagnosis in the industrial network. Journal of KONBiN, 49, 383-404. DOI: 10.2478/jok-2019-0020.

2. Billinton, R., and Allan, R.N. (1996) Reliability evaluation of power systems. New York: Plenum Press.

3. Burdzik, R., Konieczny, Ł., Figlus, T. (2013) Concept of on-board comfort vibration monitoring system for vehicles. In: Activities of Transport Telematics, Berlin: Springer, pp. 418-425. DOI: 10.1007/978-3-642-41647-7_51.

4. Caban, D., Walkowiak, T. (2019) Dependability analysis of hierarchically composed system-ofsystems. In: Proc. of the Thirteenth International Conference on Dependability and Complex Systems DepCoS-RELCOMEX, Cham: Springer, pp. 113-120. DOI: 10.1007/978-3-319-91446-6_12.

5. Chmielińska, J., Kuchta, M., Kubacki, R., Dras, M., Wierny, K. (2016) Selected methods of electronic equipment protection against electromagnetic weapon. Przeglad Elektrotechniczny Electrical Review, 92(1), 1-8, DOI:10.15199/48.2016.01.01.

6. Chrzan, M., Kornaszewski, M., Ciszewski, T. (2018) Renovation of Marine Telematics Objects in the Process of Exploitation. In: Management Perspective for Transport Telematics, Cham: Springer, pp. 337-351. DOI: 10.1007/978-3-319-97955-7_23.

7. Dabrowski, T., Bednarek, M., Fokow, K., Wisnios, M. (2012) The method of threshold-comparative diagnosing insensitive on disturbances of diagnostic signals. Przeglad Elektrotechniczny - Electrical Review, 88(11A), 93-97.

8. Duer, S. (2012) Examination of the reliability of a technical object after its regeneration in a maintenance system with an artificial neural network. Neural Computing \& Applications, 21(3), 523-534. DOI: 10.1007/s00521-011-0723-2.

9. Dyduch, J., Paś, J., Rosiński, A. (2011) The basic of the exploitation of transport electronic systems. Radom: Publishing House of Radom University of Technology.

10. Gharbi, A., Hasnaoui, O. (2014) Design and Implementation of EMC Filter Dedicated to Power Electronic Converters. In: International Conference on Electrical Sciences and Technologies in Maghreb 2014 (CISTEM), Tunis, Tunisia. DOI: 10.1109/CISTEM.2014.7076994

11. Girón, C., Rodríguez, F.J., Giménez de Urtasum, L., Borroy, S. (2018) Assessing the contribution of automation to the electric distribution network reliability. International Journal of Electrical Power \& Energy Systems, 97, 120-126. DOI: 10.1016/j.ijepes.2017.10.027.

12. Kaniewski, P., Gil, R., Konatowski, S. (2017) Estimation of UAV Position with Use of Smoothing Algorithms. Metrology and Measurement Systems, 24(1), 127-142. DOI: 10.1515/mms-2017-0013.

13. Klimczak, T., Paś, J. (2019) Selected issues of the reliability and operational assessment of a fire alarm system. Eksploatacja i Niezawodnosc - Maintenance and Reliability, 21(4), 553-561. DOI: 10.17531/ein.2019.4.3.

14. Kolarovszki, P., Vaculík, J., Hofmann L. (2013) Identification of postal mails and crates by new developed UHF RFID antenna. Transport and Telecommunication, 14(2), 130-142. DOI: 10.2478/ttj-2013-0011.

15. Kostrzewski, M. (2018) Analysis of selected acceleration signals measurements obtained during supervised service conditions - study of hitherto approach. Journal of Vibroengineering, 20, 1850-1866.

16. Krzykowska, K., Krzykowski, M. (2019) Forecasting Parameters of Satellite Navigation Signal through Artificial Neural Networks for the Purpose of Civil Aviation. International Journal of Aerospace Engineering, 1-11. DOI: 10.1155/2019/7632958. 
17. Kukulski, J., Jacyna, M., Gołębiowski, P. (2019) Finite Element Method in Assessing Strength Properties of a Railway Surface and Its Elements. Symmetry, 11, 1014. DOI: 10.3390/sym11081014.

18. Łabowski, M., Kaniewski, P. (2015) Motion Compensation for Unmanned Aerial Vehicle's Synthetic Apperture Radar. In: Signal Processing Symposium SPSympo 2015, Debe, Poland, 184-188. DOI: $10.1109 /$ SPS.2015.7168304.

19. Lheurette, E. (eds.) (2013) Metamaterials and Wave Control. London: ISTE and Wiley.

20. Losurdo, F., Dileo, I., Siergiejczyk, M., Krzykowska, K., Krzykowski, M. (2017) Innovation in the ICT infrastructure as a key factor in enhancing road safety. A multi-sectoral approach. In: Proceedings 25th International Conference on Systems Engineering ICSEng 2017; Las Vegas: IEEE Computer Society Conference Publishing Services (CPS), 157-162. DOI: 10.1109/ICSEng.2017.69.

21. Matyszkiel, R., Polak, R., Lubkowski, P., Laskowski. D. (2019) Mechanisms of immunization of broadband radio stations for targeted interference. In: Proceedings XII Conference on Reconnaissance and Electronic Warfare Systems, Oltarzew, Poland. DOI: 10.1117/12.2524561.

22. Melit, M., Nekhoul, B., Khelifi, B., Boudjerda, N. (2014) Using the Matrix Pencil in order to analyze the disturbances induced by the radiation of static converters. International Journal of Electrical Power \& Energy Systems, 62, 258-264. DOI: 10.1016/j.ijepes.2014.04.047.

23. Nicolae, P.-M., Mihai, G., Nicolae, I.-D., Duta, M. (2010) Aspects Concerning the Conducted Electromagnetic Disturbances Owing to Static Converters. In: Asia-Pacific International Symposium on Electromagnetic Compatibility, Beijing, China, 2010, pp. 957-960

24. Niknejad Ali, M. (2007) Electromagnetics for High-Speed Analog and Digital Communication Circuits. Cambridge: Cambridge University Press, 2007.

25. Paś, J. (2015) Operation of electronic transportation systems. Radom: Publishing House University of Technology and Humanities.

26. Paś, J., Rosiński, A., Szulim, M., Łukasiak J. (2020) Modelling the Safety Levels of ICT Equipment Exposed to Strong Electromagnetic Pulses. In: Proceedings of the 14th International Conference on Dependability of Computer Systems DepCoS-RELCOMEX 2019, Cham: Springer, 393-401. DOI: 10.1007/978-3-030-19501-4_39.

27. Piegdoń, I., TchórzewskA-CiIeślak, B., Eid, M. (2018) Managing the risk of failure of the water supply network using the mass service system. Eksploatacja $i$ Niezawodnosc - Maintenance and Reliability, 20(2), 284-291. DOI: 10.17531/ein.2018.2.15.

28. Piersanti, S., Orlandi, A., Paulis de, F. (2018) Electromagnetic Absorbing materials design by optimization using a machine learning approach. IEEE Transactions on Electromagnetic Compatibility, 1-8. DOI: 10.1109/TEMC.2018.2871879.

29. PN-EN 50121-3-2:2017 Railway applications - Electromagnetic compatibility - Part 3-2: Rolling stock - Apparatus.

30. PN-EN 55016-2-1:2014 Specification for radio disturbance and immunity measuring apparatus and methods - Part 2-1: Methods of measurement of disturbances and immunity - Conducted disturbance measurements.

31. PN-EN 55016-4-2:2011 + A1:2014 Specification for radio disturbance and immunity measuring apparatus and methods - Part 4-2: Uncertainties, statistics and limit modelling - Measurement instrumentation uncertainty.

32. RajaPriyanka, D., ShanmugaPriya, G., Sabashini, R., Jacintha, V.M.E. (2017) Power generation and energy management in railway system. In: Third International Conference on Science Technology Engineering \& Management (ICONSTEM), Chennai, 949-954, DOI: 10.1109/ICONSTEM.2017.8261343.

33. Reddig, K., Dikunow, B., Krzykowska, K. (2018) Proposal of big data route selection methods for autonomous vehicles. Internet Technology Letters, 1(36), 1-6. DOI: 10.1002/it12.36.

34. Siergiejczyk, M., Krzykowska, K., Rosiński, A. (2017) Evaluation of the influence of atmospheric conditions on the quality of satellite signal. In: Marine Navigation, London: CRC Press/Balkema, 121-128.

35. Siergiejczyk, M., Paś, J., Dudek, E. (2017) Reliability analysis of aerodrome’s electronic security systems taking into account electromagnetic interferences. In: Safety and Reliability - Theory and Applications - Proceedings of the 27th European Safety and Reliability Conference, London: CRC Press/Balkema, 2285-2292.

36. Siergiejczyk, M., Paś, J., Rosiński, A. (2015) Modeling of process of maintenance of transport telematics systems with regard to electromagnetic interferences. In: Tools of Transport Telematics, Cham: Springer-Verlag, 99-107. DOI: 10.1007/978-3-319-1577-5_10.

37. Siergiejczyk, M., Rosiński, A., Paś, J. (2016) Analysis of unintended electromagnetic fields generated by safety system control panels. Diagnostyka, 17(3), 35-40. 
38. Siergiejczyk, M., Rosiński, A., Dziula, P., and Krzykowska, K. (2015) Reliability-exploitation analysis of highway transport telematics systems. Journal of KONBiN, 1(33), 177-186. DOI: 10.1515/jok-2015-0015.

39. Stawowy, M., Kasprzyk, Z. (2015) Identifying and simulation of status of an ICT system using rough sets. In: Proceedings of the Tenth International Conference on Dependability and Complex Systems DepCoS-RELCOMEX, Cham: Springer, 477-484. DOI: 10.1007/978-3-319-19216-1_45.

40. Stawowy, M., and Siergiejczyk, M. (2017) Application and simulations of uncertainty multilevel models to ensure the ITS services. In: Risk, Reliability and Safety: Innovating Theory and Practice: Proceedings of ESREL 2016, London: CRC Press/Balkema, 601-605.

41. Stawowy, M., Perlicki, K., and Sumiła, M. (2017) Comparison of Uncertainty Multilevel Models to Ensure ITS Services. In: Safety and Reliability - Theory and Applications - Proceedings of the 27th European Safety and Reliability Conference; London: CRC Press/Balkema, 2647-2652.

42. Sunitha, K., and Thomas Joy, M. (2018) Effect of Soil Conditions on the Electromagnetic Field from an Impulse Radiating Antenna and on the Induced Voltage in a Buried Cable. IEEE Transactions on Electromagnetic Compatibility, 1-8. DOI: 10.1109/TEMC.2018.2844205.

43. Urbaniak, M., Kardas-Cinal, E., Jacyna, M. (2019) Optimization of Energetic Train Cooperation. Symmetry, 11, 1175. DOI: 10.3390/sym11091175.

44. Vašata, J., Doleček, R. (2016) Electromagnetic compatibility and lightning current impacts in the railway equipment buildings. In: 26th Conference Radioelektronika 2016, Košice, Slovak Republic. DOI: 10.1109/RADIOELEK.2016.7477417.

45. Wasiak, M., Jacyna-Gołda, I., Markowska, K., Jachimowski, R., Kłodawski, M., Izdebski, M. (2019) The use of a supply chain configuration model to assess the reliability of logistics processes. Eksploatacja $i$ Niezawodnosc-Maintenance and Reliability, 21(3), 367-374. DOI: 10.17531/ein.2019.3.2.

46. White, R.D., McCormack, L.M., Hooper, P.W. (2006) Electrical System Integration, Electromagnetic Compatibility (EMC) Interface Management of Railway Electrification Systems. HKIE Transactions, 13(1), 55-59. DOI: 10.1080/1023697X.2006.10668032.

47. Wróbel, Z. (2018) The Electromagnetic Compatibility in Researches of Railway Traffic Control Devices. In: Analysis and Simulation of Electrical and Computer Systems, Cham: Springer, 275-287. DOI: 10.1007/978-3-319-63949-9_17. 